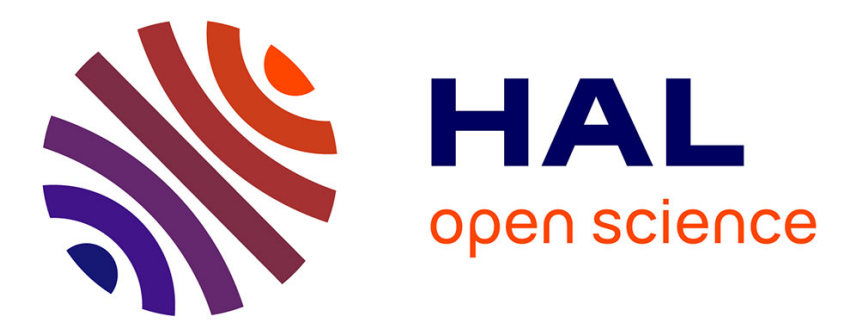

\title{
Polyaromatic Luminescent Nanocrystals for Chemical and Biological Sensors
}

E. Botzung-Appert, Virginie Monnier, T Ha Duong, R. Pansu, A. Ibanez

\section{To cite this version:}

E. Botzung-Appert, Virginie Monnier, T Ha Duong, R. Pansu, A. Ibanez. Polyaromatic Luminescent Nanocrystals for Chemical and Biological Sensors. Chemistry of Materials, 2004, 16 (9), pp.1609 1611. 10.1021/cm0311628. hal-01846285

\section{HAL Id: hal-01846285 \\ https://hal.science/hal-01846285}

Submitted on 23 Jul 2018

HAL is a multi-disciplinary open access archive for the deposit and dissemination of scientific research documents, whether they are published or not. The documents may come from teaching and research institutions in France or abroad, or from public or private research centers.
L'archive ouverte pluridisciplinaire HAL, est destinée au dépôt et à la diffusion de documents scientifiques de niveau recherche, publiés ou non, émanant des établissements d'enseignement et de recherche français ou étrangers, des laboratoires publics ou privés. 


\section{Polyaromatic Luminescent Nanocrystals for Chemical and Biological Sensors}

\author{
E. Botzung-Appert, ${ }^{\dagger}$ V. Monnier, ${ }^{\dagger}$ T. Ha Duong, ${ }^{\ddagger}$ \\ R. Pansu, ${ }^{\mp}$ and A. I banez*,†
}

Laboratoire de Cristallographie, CNRS, UPR 5031 associée à I'U niversité J. Fourier et à I'IN PG, BP 166,

F-38042 Grenoble Cedex 9, France, and Laboratoire Photochimie et Photophysique Mol éculaire et Supramoléculaire, ENS-Cachan, 61 Avenue de Président Wilson, 94235 Cachan Cedex, France

Received October 27, 2003

Revised Manuscript Received March 15, 2004

Recently, we have engineered new hybrid organicinorganic materials through a simple and generic preparation of stable organic nanocrystals grown in solgel thin films prepared by spin-coating. ${ }^{1-3}$ This process is based on the confined nucleation and growth of dyes in the pores of sol-gel networks. These nanocomposite coatings not only combine the optical properties of organic phases (luminescence, NLO properties, etc.) with those of amorphous inorganic materials (high stability, convenient processing, and shaping) but also the advantages of nanocrystals: preparation of low diffusing samples for visible or IR laser beams and higher stability than dispersed molecules.

The aim of this work is to design a new type of fluorescent nanosensors through the preparation of organic luminescent nanocrystals grown in silicate films. Indeed, these nanocomposite coatings exhibit an open porosity which allows a great reactivity between the nanocrystals and their chemical surroundings. Besides, sol-gel thin films are already involved in the fabrication of gas sensors. ${ }^{4}$ The adjustment of sol-gel porosity at the nanometer scale would all ow the protection of these nanosensors against unwanted interactions, the silicate matrix playing thus the role of a filter in size, charge, and polarity. Moreover, organic nanocrystals exhibit higher photostability and luminosity than isolated molecules dispersed in solutions or in solid matrixes such as sol-gel or polymers. We have sel ected two polyaromatic dyes, rubrene $(5,6,11,12$-tetraphenylnaphthacene) and tetracene (2,3-benzantracene), which exhi bit high fluorescence efficiency in the crystal state. We have separated the detection and signalization functions, as previously made for latex: ${ }^{5}$ the polyaromatic nanocrystals act as the signaling part while the probe molecules adsorbed at the surface of the nanocrystals constitute the detection function. The first molecular probe selected was Methylene Blue (MB, (7-

* Corresponding author. Phone: (33) 4768878 05. Fax: (33) 476 8810 38. E-mail: alain.ibanez@grenoble.cnrs.fr.

+ CNRS.

‡ ENS-Cachan.

(1) Ibanez, A.; Maximov, S.; Guiu, A.; Chaillout, C.; Baldeck, P. L. Adv. Mater. 1998, 10, 1540.

(2) Sanz, N.; Gaillot, A. C.; Baldeck, P. L.; Ibanez, A. J . Mater. Chem. 2000, 10, 2723.

(3) Zaccaro, J .; Sanz, N.; Botzung Appert, E.; Baldeck, P. L.; I banez, A. C. R. Phys. 2002, 3, 463.

(4) Calvo-Muñoz, M. L.; Truong, T. T.; Tran-Thi, T. H. Sens. Actuators B 2002, 87, 173.

(5) Méallet-Renault, R.; Denjean, P.; Pansu, R. B. Sens. Actuators B 1999, 59, 108. (dimethylamino)-phenothiazin-3-ylidene)-dimethylammonium) used in aqueous solutions as a redox sensor.

The sol-gel thin films are prepared by spin-coating. We start from solutions containing a solvent, the dye, silicon alkoxides, and water, which are inserted in airtight flasks. To specify the role of the host sol-gel matrix, several alkoxide precursors have been used in this work. Thus, thin films are obtained from TMOS (tetramethoxysilane), and equimolar alkoxide mixtures of TMOS/MTMOS (methyltrimethoxysilane) or TMOS/ MDMS (methyldimethoxysilane). The TMOS and TMOS/ MTMOS sols are synthesized under acid $(\mathrm{HCl}, \mathrm{pH} \approx$ 1.5) catalyzed conditions by one-step hydrolysis and condensation of the alkoxide precursors for 3 days at $80{ }^{\circ} \mathrm{C}$ with one water molecule per $-\mathrm{OR}$ function ( $\mathrm{h}=$ $\left.\left[\mathrm{H}_{2} \mathrm{O}\right] /[-\mathrm{OR}]=1\right)$. In the case of TMOS/MDMS sols, a two-step hydrolysis - condensation is used under neutral conditions: $12 \mathrm{~h}$ at $60{ }^{\circ} \mathrm{C}$ with $\mathrm{h}=0.2$ followed by 3 days at $60{ }^{\circ} \mathrm{C}$ with $\mathrm{h}$ made up to 0.6 . Tetrahydrofuran (THF) has been used to dissolve the dyes, rubrene or tetracene, and to mix water of hydrolysis with alkoxide precursors; the molar ratio solvent/al koxide $\mathrm{s}$ is set to 5 for all the thin films studied here. The $60-80{ }^{\circ} \mathrm{C}$ heating all ows rapid dissolution of the organic powder and enhancement of the hydrolysis and condensation kinetics, leading to the formation of silicate chains dispersed in the solution. This sol aging is necessary to control the sol viscosity, around 10-20 cps, to obtain high-quality films, to ensure the control of particle growth, and to avoid the crystal coalescence. The resulting sols, which are stable for several weeks, are deposited at room temperature by spin-coating onto thin microscope slides with a rotation speed of $4000 \mathrm{rpm}$. Thus, films of around $0.5-\mu \mathrm{m}$ thick have been prepared. These nanocomposite coatings are then stabilized by annealing at $200{ }^{\circ} \mathrm{C}$. The dye concentration, expressed as the molar ratio $\mathrm{d}=$ organic/alkoxide $\approx 10^{-3}-10^{-2}$, depends on the dye solubility in THF, the nature of the host matrix, and the desired particle sizes. The latter was targeted here between 250 and $500 \mathrm{~nm}$ in diameter to facilitate the nanocrystal observations and characterizations by optical confocal microscopy.

Rubrene and tetracene nanocrystals were first visualized through fluorescence confocal microscopy (FCM) excited by the 488-nm beam of a 15-mW Argon laser. The confocal laser scanning microscope is a LSM410 from Zeiss. Figure 1 shows a typical FCM image of our nanocomposite thin films. One can see well-dispersed and embedded organic nanocrystals in the silicate coating. However, we are limited in FCM by the weak resolution of this technique: around $200 \mathrm{~nm}$ in the $x-y$ plane and 500-600 nm in the thickness, z. For this reason, we have al so characterized the films by transmission electron microscopy (TEM). In this case, the coatings are deposited onto sodium chloride crystal plates. These substrates are dissolved in water and the films are then placed on a copper grid for TEM characterizations. Thus, one can observe well-defined molecular crystals with a spherical shape and narrow size distribution, ranging for example between 300 and 500 $\mathrm{nm}$ for the sample displayed in Figure 2. 

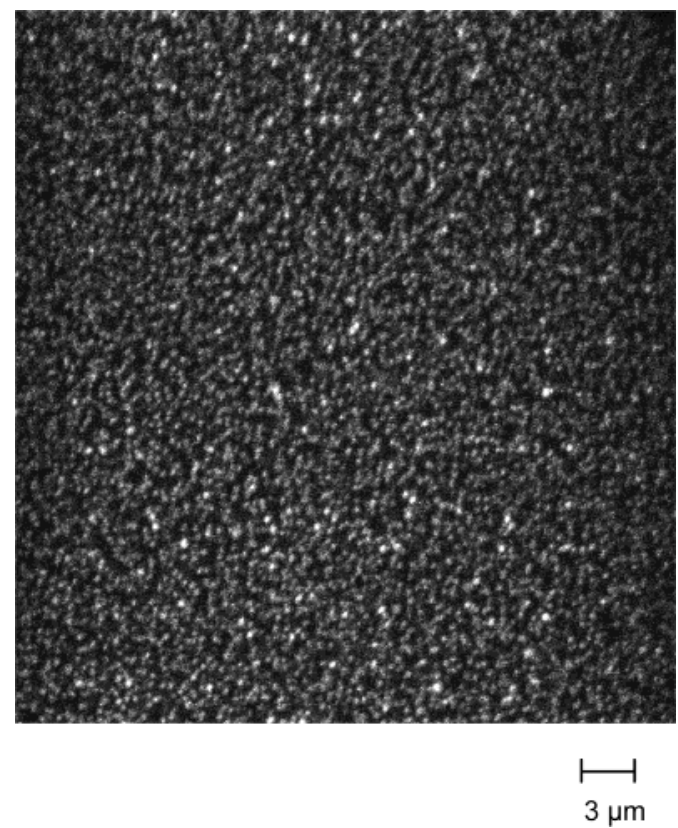

Figure 1. Confocal fluorescence microscopy image of rubrene nanocrystals grown in a TMOS/MTMOS sol-gel thin film.

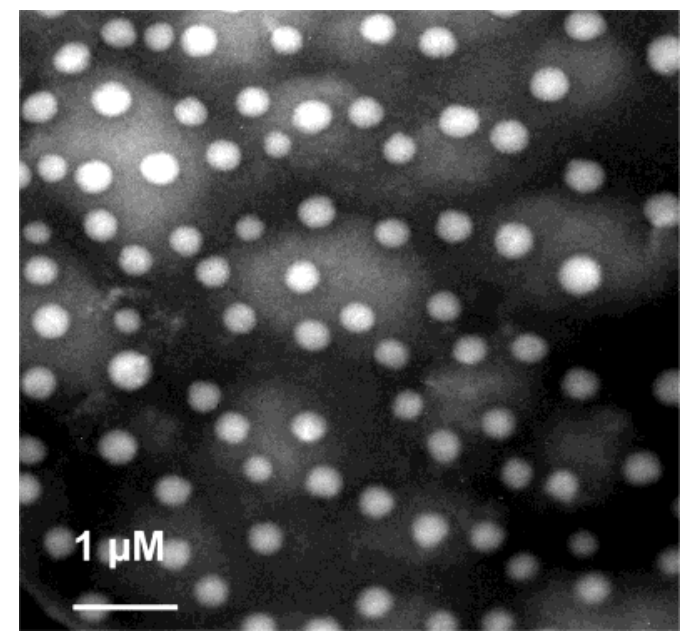

Figure 2. TEM image of rubrene nanocrystals.

We have measured the fluorescence spectra of rubrene and tetracene nanocrystals with a Faber SD2000 spectrometer. The significant overlap of these emissions with the MB absorption band (Figure 3) ensures a good energy transfer between the nanocrystals and the MB colored form, which can thus act as a quenching site. We have also measured the fluorescence decays (excitation wavelength of $495 \mathrm{~nm}$ ) of rubrene and tetracene nanocrystals in different sol-gel matrixes, for various particle sizes (between 200 and $800 \mathrm{~nm}$ in diameter), for raw thin films, and after addition of pure water. We have observed monoexponential decays with lifetimes of 13 and $5 \mathrm{~ns}$, for rubrene and tetracene nanocrystals, respectively, with no effect of the particle sizes or the presence of water. On the other hand, the nature of the involved matrixes does not modify significantly the fluorescence decays. This is due to the dye aggregation in nanocrystals and to the weak interactions existing between the polyaromatic molecules located at the surface of the nanocrystal and the silicate network. ${ }^{6}$ Figures 4 and 5 show typical fluorescence decay curves recorded for rubrene and tetracene thin films. When

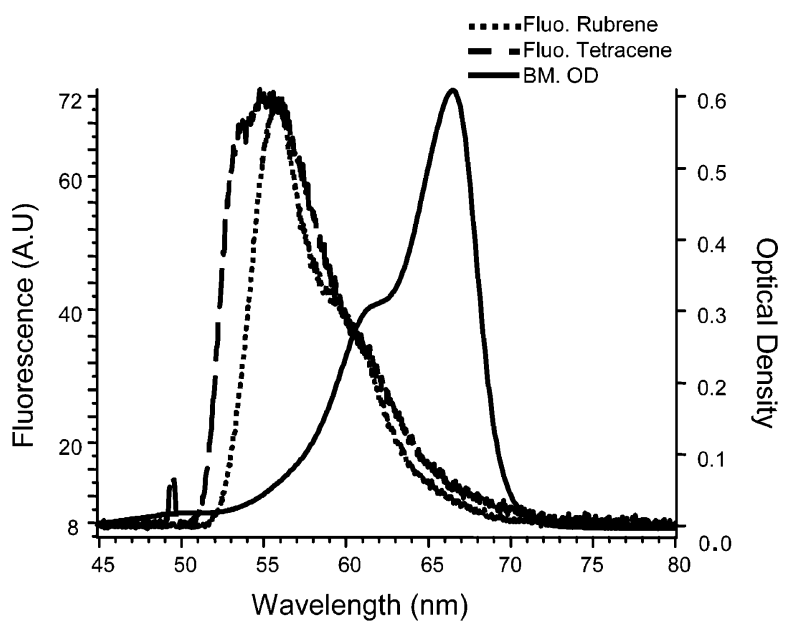

Figure 3. Overlappings between the fluorescence spectra of rubrene and tetracene nanocrystals and the absorption spectrum of Methylene Blue.

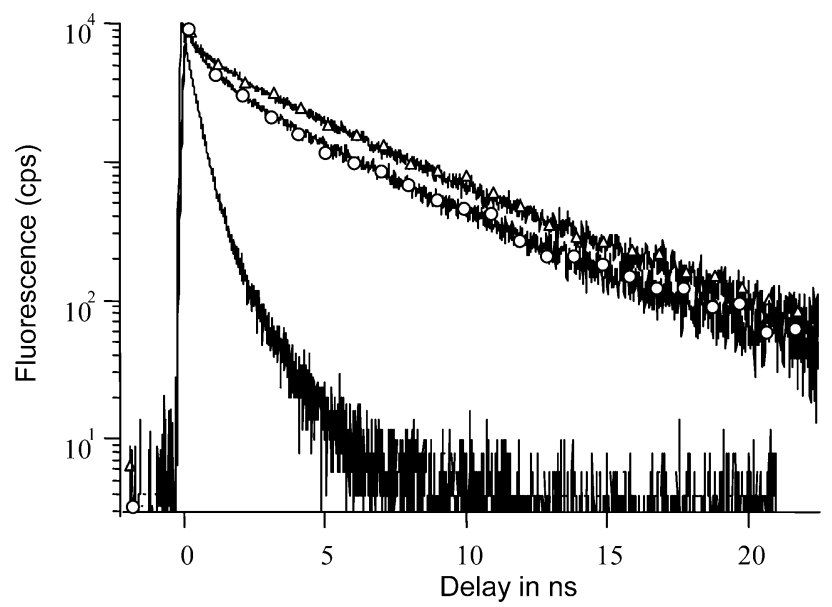

Figure 4. Fluorescence decays of as-grown tetracene nanocrystals (triangles), after the addition of $1 \mathrm{mmol} / \mathrm{L} \mathrm{MB}$ solution (solid line), and after water rinsing (circles).

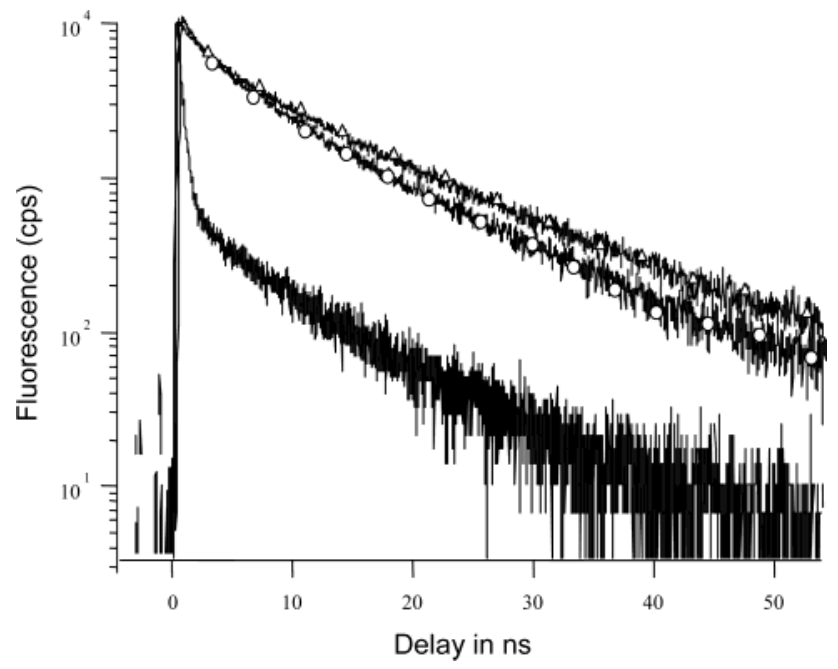

Figure 5. Fluorescence decays of raw rubrene nanocrystals (triangles), after the addition of $1 \mathrm{mmol} / \mathrm{L} \mathrm{MB}$ solution (solid line), and after the reduction of Methylene Blue in the presence of glucose (circles).

drops of aqueous solutions containing low MB concentrations $\left(1 \times 10^{-3} \mathrm{~mol} \cdot \mathrm{L}^{-1}\right.$, natural $\left.\mathrm{pH}\right)$ are deposited onto the nanocomposite coating, one can note a strong 


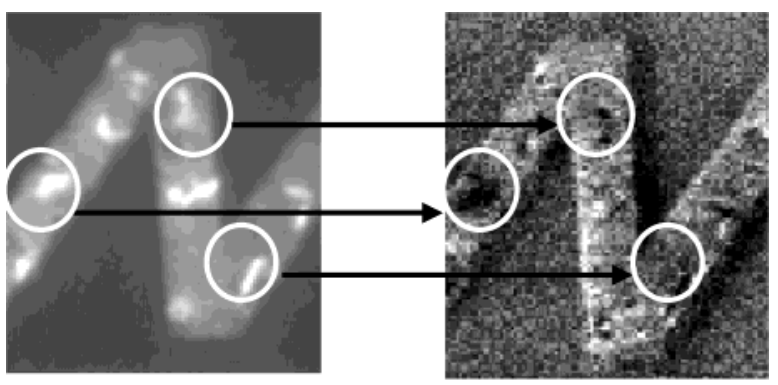

(a)

(b)

Figure 6. Fluorescent confocal microscopy images of raw fluorescent rubrene microcrystals (a) and after the addition of $1 \mathrm{mmol} / \mathrm{L} \mathrm{MB}$ solution (b).

decrease of the fluorescence intensities: 1 order of magnitude for rubrene and 3 orders for tetracene nanocrystals. This is due to the nanocrystal functionalization by MB molecules adsorbed on their surfaces. Indeed, the excitation, delocalized in the whole nanocrystal, can reach the quenching site created by the adsorbed MB probe. This quenching of the fluorescence has been confirmed by the visualization of fluorescent microcrystals by confocal microscopy before and after the addition of the MB solution. In this case, we have used larger crystal sizes to make easier the sample observation. Thus, we can see on Figure 6 that the majority of fluorescent microcrystals $(1-2 \mu \mathrm{m})$ is quenched by the MB addition. Finally, when $M B$ is washed (Figure 4) or when glucose in $\mathrm{KOH}^{7}$ is added to the MB solution (Figure 5), one find again the fluorescence decays of tetracene and rubrene nanocrystals. In the first case (Figure 4) the MB quenching site is removed by rinsing with water. On the other hand, the $M B$ is a redox indicator with a potential of $-0.04 \mathrm{~V}$ at $\mathrm{pH}=7$ which is blue in the presence of oxygen and

(6) Sanz, N.; Zaccaro, J .; Delmotte, L.; Le Luyer C.; I banez, A. J . Solid State Chem. 2002, 165, 25.

(7) Adamcíková, L.; Sevcík, P. J . Chem. Educ. 1998, 75, 1580. colorless in the presence of a reducing sugar for example. In the second case (Figure 5), when MB is reduced by glucose, as there is not overlapping between the absorption band of the colorless MB form and the fluorescence of polyaromatic nanocrystals, the energy transfer between the molecular probe and signaling particle is blocked. Thus, the sensor potentialities of organic nanocrystals functionalized by indicators is wellillustrated by this typical example of the redox oxygen titration in aqueous solutions by glucose.

We have thus demonstrated the basic working principles of fluorescent organic nanocrystals as nanosensors by adsorbing on them indicators. The signalization function is based on polyaromatic nanocrystals which exhibit good stability and photostability when compared to typical dispersed dyes and a simple fluorescence signature (monoexponential decay) in comparison with inorganic nanocrystals. ${ }^{8}$ The fluorescence of organic nanocrystals is quenched through the adsorption of probe molecules on their surface. This strong effect, clearly displayed in Figure 6 , is due to the large delocalization of the initial excitation in the whole nanocrystal which can reach the quenching site, that is, a probe molecule adsorbed at the nanocrystal surface. We are now going to follow currently the decrease in luminescence with the concentration of Methylene Blue and other target molecules to specify the high sensitivity of these nanosensors. Finally, this new type of nanosensors exhibits other significant advantages such as low preparation cost and easy nanocrystal functionalizations with the possibility to use a lot of indicators devel oped in analytical chemistry. ${ }^{9}$ Moreover, the sol-gel matrixes can play the role of a filter in size (pores), charge, and polarity.

CM0311628

(8) Schlegel, G.; Bohnenberger, J .; Potapova, I.; Mews, A. Phys. Rev. Lett. 2002, 88, 137401.

(9) Bishop, E. Indicators, 1st ed.; Pergamon: Oxford, 1972. 